\title{
ERYTHROMYCIN STIMULATES GASTRIC EMPTYING AFTER ESOPHAGECTOMY WITH GASTRIC REPLACEMENT: A RANDOMIZED CLINICAL TRIAL
}

Michael Burt, MD, PhD ${ }^{\mathrm{a}}$

Andrew Scott, MD ${ }^{\mathrm{b} \$}$

William C. Williard, MD ${ }^{\mathrm{a} \xi}$

Rodney Pommier, $\mathrm{MD}^{\mathrm{a}}$

Samuel Yeh, MD ${ }^{\text {bs }}$

Manjit S. Bains, $\mathrm{MD}^{\mathrm{a}}$

Allan D. Turnbull, $\mathrm{MD}^{\mathrm{c} \S}$

Joseph G. Fortner, MD ${ }^{\mathrm{a}}$

Patricia M. McCormack, MD

Robert J. Ginsberg, MD
Delayed gastric emptying after esophagogastrectomy can pose a significant early postoperative problem. Because erythromycin, which stimulates the gastric antral and duodenal motilin receptor, has been shown to significantly increase gastric emptying in patients with diabetic gastroparesis; we decided to evaluate its effect on gastric emptying after esophagogastrectomy. Methods: Twenty-four patients (18 men and six women, age range 41 to 79 years, median 66 years) were randomized to receive either erythromycin lactobionate ( $200 \mathrm{mg}$ in $50 \mathrm{ml}$ normal saline solution intravenously) $(n=13)$ or placebo $(50 \mathrm{ml}$ normal saline solution intravenously $(n=11) 11$ days after esophagogastrectomy (with pyloric drainage procedure). After erythromycin or placebo had been infused over a 15-minute period, patients ingested a solid meal (scrambled egg with bread) labeled with technetium $99 \mathrm{~m}$ sulfur colloid ( $500 \mu \mathrm{Ci}$ ) over approximately 15 minutes. Dynamic images of the stomach were then acquired over 90 minutes in the supine position by gamma imaging. Results were expressed as percentage of counts retained in the stomach (percent gastric retention) over time. Results: There were no side effects of erythromycin. In the placebo group, the mean percent of radiolabeled meal retained in the stomach after 90 minutes was $88 \%$, which was significantly greater than in the erythromycin group, 37\% ( $p<0.001)$. In addition, analysis of covariance demonstrated that the rate of gastric emptying (slope of the line) was significantly greater in the erythromycin-treated group than in the placebo group $(p<0.0001)$. Conclusion: Early satiety after esophagogastrectomy may be due to delayed gastric emptying and not due to a decrease in the gastric reservoir. Intravenous erythromycin significantly improves gastric emptying in patients after esophagogastrectomy by stimulating gastric motility. (J THORAC CARDIOvasc Surg 1996;111:649-54)
Das elayed gastric emptying after gastric, pancreatic, and esophageal operations is a common event, occurring in up to $50 \%$ of patients. ${ }^{1-4}$ When clini-

From the Division of Thoracic Surgery, a Department of Surgery, the Nuclear Medicine Division, 'bepartment of Radiology, and the Gastric and Mixed Tumor Service; ${ }^{\circ}$ Department of Surgery, Memorial Sloan-Kettering Cancer Center, New York, N.Y.

Read at the Seventy-fifth Annual Meeting of The American Association for Thoracic Surgery, Boston, Mass., April 23-26, 1995.

Received for publication April 4, 1995; revisions requested August 9, 1995; revisions received Oct. 20, 1995; accepted for publication Nov. 22, 1995.

Address for reprints: Michael Burt, $\mathrm{MD}, \mathrm{PhD}$, Division of Thoracic Surgery, Department of Surgery, Memorial Sloan-Kettering Cancer Center, 1275 York Ave., New York, NY 10021.

${ }^{5}$ By invitation.

Copyright $(1) 1996$ by Mosby-Year Book, Inc.

$0022-5223 / 96 \$ 5.00+0 \quad \mathbf{1 2 / 6 / 7 0 8 7 7}$ cally significant, medical therapy is instituted, usually with limited success. Metaclopramide, bethanechol, domperidone, and cisapride have been studied in patients, with little success. ${ }^{5-7}$

Erythromycin, a motilin agonist, ${ }^{8}$ has been demonstrated to improve gastric emptying in normal subjects, ${ }^{9}$ patients with diabetic gastroparesis, ${ }^{10}$ and patients with postvagotomy gastroparesis. ${ }^{11}$

With these preliminary observations, we designed a prospective randomized trial to evaluate the efficacy of erythromycin in improving gastric emptying in human beings after esophagogastrectomy.

\section{Patients and methods}

From October 1990 to October 1992, 24 patients undergoing esophagogastrectomy and pyloric drainage were randomized to receive erythromycin $(n=13)$ or placebo ( $n=11$ ) just before a radionuclide gastric emptying study. All patients signed an informed consent form to participate in this study, after having been approved by our 
Table I. Demographics of the 24 patients randomized to receive erythromycin or placebo

\begin{tabular}{lccc}
\hline & $\begin{array}{c}\text { Erythromycin } \\
(n=13)\end{array}$ & $\begin{array}{c}\text { Placebo } \\
(n=11)\end{array}$ & $\begin{array}{c}p \\
\text { Value }\end{array}$ \\
\hline Median age (yr) & 64 & 66 & NS \\
Sex & & & NS \\
$\quad$ Male & 11 & 7 & \\
$\quad$ Female & 2 & 4 & NS \\
Histologic type & & & \\
$\quad$ Adenocarcinoma & 7 & 6 & \\
$\quad$ Squamous cell carcinoma & 6 & 5 & NS \\
Location of tumot & & & \\
$\quad$ Gastroesophageal junction & 5 & 4 & \\
$\quad$ Lower third of esophagus & 6 & 3 & \\
$\quad$ Middle third of esophagus & 2 & 2 & \\
$\quad$ Upper third of esophagus & 0 & 2 & NS \\
Operation & & & \\
$\quad$ Ivor Lewis & 10 & 7 & \\
$\quad$ Transhiatal & 0 & 3 & \\
$\quad$ Thoracoabdominal & 2 & 0 & \\
$\quad$ Transabdominal & 1 & 1 & \\
Drainage procedure & & & NS \\
$\quad$ Pyloromyectomy & 9 & 3 & \\
$\quad$ Pyloromyotomy & 3 & 6 & \\
$\quad$ Pyloroplasty & 1 & 2 & \\
\hline
\end{tabular}

NS, Not significant.

institutional review board. All patients underwent a barium swallow on days 6 to 8 to ensure that the esophagogastrostomy was intact. Patients were started by receiving liquids and advanced to solid foods by days 10 or 11 . On the eleventh postoperative day, after an overnight fast, the patients received an intravenous infusion of erythromycin lactobionate $(200 \mathrm{mg}$ in $50 \mathrm{ml}$ normal saline solution) over 15 minutes, or else placebo ( $50 \mathrm{ml}$ normal saline solution). After infusion of the erythromycin or placebo, patients ingested a standardized meal consisting of one scrambled egg labeled with $500 \mu \mathrm{Ci}$ of technetium $99 \mathrm{~m}$ sulfur colloid, a slice of white bread, and $150 \mathrm{ml}$ of water in 10 to 15 minutes.

Immediately after finishing their meal, the patients were positioned supine under an ADAC Genesys gamma camera (Milpetas, Calif.) equipped with a low-energy, all-purpose collimator and linked to a dedicated computer system. Dynamic images of the anterior part of the chest and upper part of the abdomen were then acquired every 1 minute for 90 minutes. Regions of interest were then manually drawn around the gastric reminant, and derived time-activity curves were corrected for technetium decay. Results were expressed as the percentage of solid meal remaining in the stomach over time after completion of the meal.

Data are presented as mean \pm standard deviation. Frequency data were analyzed by $\chi^{2}$ analysis, means by unpaired $t$ test, and rate of gastric emptying by analyses of covariance. Significance was defined as $p<0.05$.

\section{Results}

Twenty-four patients were studied after randomization to erythromycin $(n=13)$ or placebo $(n=$ $11)$. They included 18 men and six women whose ages ranged from 41 to 79 years (median 66 years). Thirteen patients had adenocarcinoma and 11 had squamous cell carcinoma. The carcinoma was located in the gastroesophageal junction in nine, lower third of the esophagus in nine, middle third in four, and upper third in two. The operation performed was a standard Ivor Lewis resection in 17, transhiatal in three, left thoracoabdominal in two, and transabdominal in two. All 24 patients underwent a drainage procedure: pyloromyectomy in 12 , pyloromyotomy in nine, and pyloroplasty in three. Table I shows that there were no significant differences in the aforementioned parameters in the two groups of patients.

No adverse side effects resulted from either the erythromycin infusion or the gastric emptying study.

Fig. 1 depicts the percentage of solid meal retained in both groups over the 90-minute study period. As noted, the group receiving erythromycin had a significant increase in gastric emptying. At 90 minutes, the erythromycin group retained $37 \% \pm 27 \%$ of the meal, which was significantly less than the $88 \% \pm 17 \%$ retained by the placebo group $(p<0.0001)$. Analysis of covariance demonstrated that the rate of gastric emptying (slope of the line) was significantly greater in the erythromycin-treated group than in the placebo group $(p<0.0001)$.

\section{Discussion}

This study suggests that patients have a delay in gastric emptying after esophagogastrectomy. When these patients ingest a radiolabled meal, approximately $88 \%$ is retained in the stomach at 90 minutes. In contrast, when healthy volunteers ingest a radiolabeled meal, only $20 \%$ to $40 \%$ is retained. ${ }^{12,13}$ Many patients experience "early satiety" after esophagectomy, and this has been attributed to the small capacity of the esophageal substitute, or to loss of the gastric reservoir function. ${ }^{4}$ This study suggests that early satiety may be due to a marked delay in gastric emptying in patients undergoing esophagectomy, at least in the early postoperative period.

Various agents have been evaluated to promote gastric emptying, such as metaclopramide, bethanechol, domperidone, and cisapride, but none has been found satisfactory. ${ }^{5-7}$ Erythromycin, on the other hand, was first found to markedly increase 


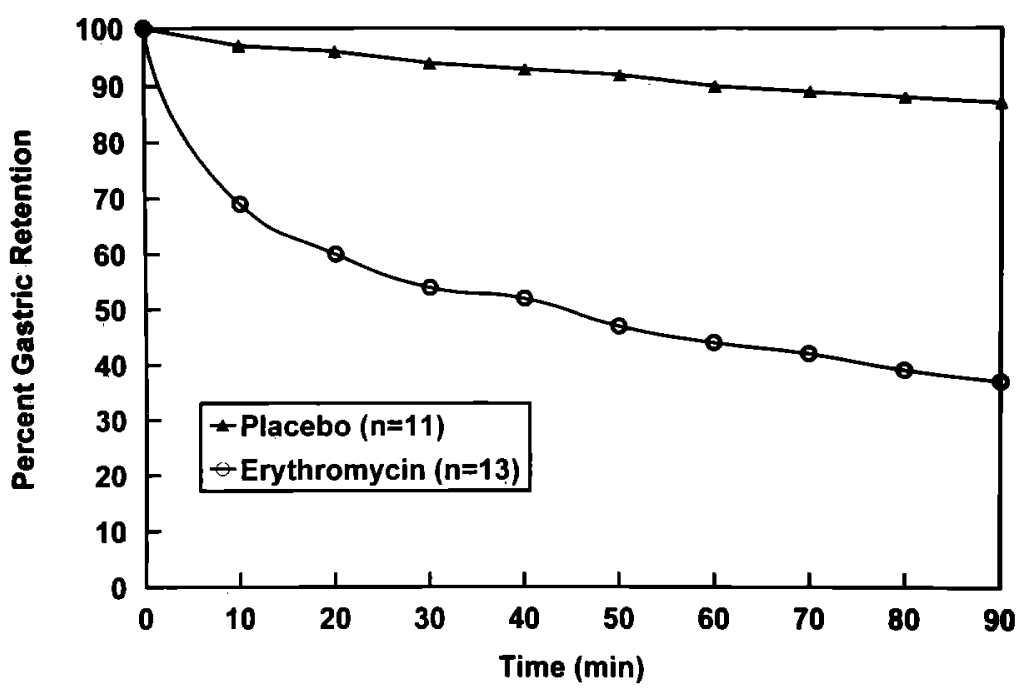

Fig. 1. Results of gastric emptying study. At 90 minutes, patients receiving erythromycin had significantly less radionuclide meal retained in the stomach $(37 \%)$ than those receiving placebo $(88 \%)(p<0.0001)$.

gastric emptying in patients with diabetic gastroparesis. ${ }^{10,14}$ It has subsequently been shown to increase gastric emptying in other medical causes of gastroparesis, such as scleroderma ${ }^{15}$ anorexia nervosa ${ }^{16}$ cirrhosis, ${ }^{17}$ and idiopathic disorders. ${ }^{17}$

Erythromycin appears to promote gastric motility and subsequent emptying by acting as a motilin agonist. ${ }^{8}$ In vitro studies of smooth muscle demonstrate that contraction curves stimulated by erythromycin mimic those of motilin. ${ }^{18,19}$ Erythromycin, like other fourteen-member macrolides, competes with motilin for the motilin receptor on gastrointestinal smooth muscle and therefore probably acts as a motilin agonist. ${ }^{20}$ In human beings, motilin receptors have been found in the smooth muscle of the gastric antrum and duodenum. ${ }^{21}$ Evidence exists that physiologic doses of motilin stimulate interdigestive motility by inducing rhythmic phase 3 motor activity of the migrating motor complex, beginning in the gastric smooth muscle and migrating distally through the small bowel. ${ }^{22-24}$ Erythromycin has an almost identical effect on interdigestive motility. ${ }^{9,25-27}$

The role of erythromycin in the therapy of surgically induced gastroparesis of the upper gastrointestinal tract is undergoing investigation. Erythromycin by intravenous infusion significantly increased gastric emptying in dogs after vagotomy and Roux-Y antrectomy. ${ }^{28}$ Similar results were later documented in human beings after truncal vagotomy and pyloroplasty, ${ }^{29}$ partial gastrectomy, ${ }^{30}$ and truncal vagotomy and antrectomy. ${ }^{31}$
In a large trial from The Johns Hopkins Hospital, patients undergoing partial or total pancreatectomy (with distal gastrectomy or a pylorus-sparing procedure) were randomized to intravenous erythromycin (200 mg every 6 hours) or placebo from postoperative days 3 to 10 . The investigators found a significant increase in gastric emptying in the erythromycin-treated group compared with the control group. $^{32}$

Because esophagectomy entails truncal vagotomy, delayed gastric emptying is a relatively common event, but in most patients it is a relatively minor clinical problem. However, clinically significant delayed gastric emptying is noted in $4 \%$ to $6 \%$ of patients after esophagogastrectomy, ${ }^{33-35}$ with no difference between transthoracic and transhiatal techniques. Patients with a marked delay in gastric emptying may be severely debilitated. To date, no drugs have significantly relieved the problem of delayed gastric emptying after esophagogastrectomy.

In this study, we document that delayed gastric emptying is uniformly present in the early postoperative period after esophagectomy. We also show that intravenous erythromycin increases gastric emptying to the normal range. Whether these initially encouraging results translate into decreasing postoperative recovery time and length of hospital stay, while improving nutritional status and quality of life, remains to be answered by carefully designed, prospective studies. 
Another important area to be explored is the use of oral erythromycin in the outpatient setting for patients with chronic gastroparesis after esophagectomy. For most patients, gastric emptying is decreased in the supine position and increased in the sitting or upright position for 3 to 12 months after esophagogastrectomy. ${ }^{35-38}$ Still, some patients have chronic gastroparesis after esophagectomy. ${ }^{39}$

Mozwecz and associates ${ }^{11}$ described a patient with chronic gastroparesis after esophagogastrectomy who had a marked increase in gastric emptying after 2 weeks of oral erythromycin therapy $(250 \mathrm{mg}$ before each meal and at bedtime). ${ }^{11}$ This patient also had substantial lessening of symptoms. Hill and associates ${ }^{40}$ studied patients 3 months after esophagogastrectomy. One group received cisapride (10 $\mathrm{mg}$ orally three times a day) and another erythromycin (250 mg orally three times a day) for 3 days. The control group received no therapy. After the treatment period they performed a gastric emptying radionuclide study. At 4 hours the control group retained $56 \%$ of the ingested meal, the cisapride group $50 \%$, and the erythromycin group $18 \%$. The authors concluded that oral erythromycin significantly increased gastric emptying in patients 3 months after esophagogastrectomy.

Although short-term use (4 weeks) of oral erythromycin has been beneficial in diabetic gastroparesis, ${ }^{10}$ it remains to be seen whether long-term use will benefit patients with medical or surgical gastroparesis. The ideal drug for patients with chronic gastroparesis would have the following characteristics: (1) can be taken orally; (2) is long acting; (3) has no side effects; (4) will not cause tachyphylaxis, and (5) effectively increases gastric emptying to the normal range.

\section{REFERENCES}

1. Hinder RA, Esser J, DeMeester TR. Management of gastric emptying disorders following Roux-en-Y procedure. Surgery 1988;104:756-72.

2. Kraft RO, Fry WJ, DeWeese MD. Post-vagotomy gastric atony. Arch Surg 1964;88:865-72.

3. Miedema BW, Sarr MG, van Heerden JA, Nagorney DM, McIlrath DC, Ilstrup D. Complications following pancreaticoduodenectomy: current management. Arch Surg 1992;127: 945-50.

4. Collard JM, Otte JB, Reynaert M, Kastens PJ. Quality of life three years or more after esophagectomy for cancer. J THoraC CaRdiovasc Surg 1992;104:391-4.

5. Snape WJ, Battle WM, Schwartz SS, Braunstein SN, Goldstein HA, Alavi A. Metroclopramide to treat gastroparesis due to diabetes mellitus. Ann Intern Med 1982;96:444-6.

6. Horowitz M, Harding PE, Chatterton BE, Collins PJ, Shear- man DJC. Acute and chronic effects of domperidone on gastric emptying in diabetic autonomic neuropathy. Dig Dis Sci 1985;30:1-9.

7. Horowitz M, Maddox A, Harding PE, et al. Effect of cisapride on gastric and esophageal emptying in insulin-dependent diabetes mellitus. Gastroenterology 1987;92:1899-907.

8. Itoh $Z$, Nakaya $M$, Suzuki $T$, et al. Erythromycin mimics exogenous motilin in gastrointestinal contractile activity in the dog. Am J Physiol 1984;247:G688-94.

9. Sarna SK, Soergel KH, Koch TR, et al. Effects of crythromycin on human gastrointestinal motor activity in the fasted and fed states. Gastroenterology 1989;96:A440.

10. Janssens J, Peeters TL, Vantrappen G, et al. Improvement of gastric emptying in diabetic gastroparesis by erythromycin. $\mathrm{N}$ Engl J Med 1990;322:1028-31.

11. Mozwecz H, Pavel D, Pitrak D, Orellana P, Schlesinger PK Layden TJ. Erythromycin stearate as prokinetic agent in postvagotomy gastroparesis. Dig Dis Sci 1990;35:902-5.

12. Edelbroek MAL, Horowitz M, Wishart JM, Akkermans LMA. Effects of erythromycin on gastric emptying, alcohol absorption and small intestinal transit in normal subjects. J Nucl Med 1993;34:582-8.

13. Mantides A, Xynos E, Chrysos E, Georgopoulos N, Vassilakis JS. The effect of erythromycin in gastric emptying of solids and hypertonic liquids in healthy subjects. Am J Gastroenterol 1993;88:198-202.

14. Desautels SG, Hutson W, Christian PE, Moore JG, Datz FL. Gastric emptying response to variable oral erythromycin dosing in diabetic gastroparesis. Dig Dis Sci 1995;40:141-6.

15. Fiorucci S, Distrutti E, Gerli R, Morelli A. Effect of erythromycin on gastric and gallbladder emptying and gastrointestinal symptoms in scleroderma patients is maintained medium term. Am J Gastroenterol 1994;89:550-5.

16. Stacher G, Peeters TL, Bergmann H, et al. Erythromycin effects on gastric emptying, antral motility and plasma motilin and pancreatic polypeptide concentrations in anorexia nervosa. Gut 1993;34:166-72.

17. Chaussade S, Sogni P, Couturier D, Guerre J. Intravenous erythromycin and delayed gastric emptying. Gastrointest Endose 1992;38:733.

18. Peeters T, Matthijs G, Depoortere I, et al. Erythromycin is a motilin receptor agonist. Am J Physiol 1989;257:G470-4.

19. Itoh Z, Omura S. Motilide, a new family of macrolide compounds mimicking motilin. Dig Dis Sci 1987;32:915.

20. Kondo Y, Torii K, Omura S, et al. Erythromycin and its derivatives with motilin-like biological activities inhibit the specific binding of I-125-motilin to duodenal muscle. Biochem Biophys Res Commun 1988;150:877-82.

21. Peeters T, Bormans V, Vantrappen G. Comparison of motilin binding to crude homogenates of human and canine gastrointestinal smooth muscle tissue. Regul Pept 1988;23: 171-82.

22. Itoh Z, Takeuchi S, Aizawa I, et al. Changes in plasma motilin concentration and gastrointestinal contractile activity in conscious dogs. Dig Dis Sci 1978;23:929-35.

23. You $\mathrm{CH}$, Chey W, Lee KY. Studies on plasma motilin concentration and interdigestive migrating motor complex in man. Dig Dis Sci 1979;24:497-500.

24. Peeters TL, Vantrappen G, Janssens J. Fasting motilin levels are related to the interdigestive motility complex. Gastroenterology 1980;79:716-9.

25. Zara GP, Qin XY, Pilot MA, Thompson HH, Maskell JP 
Erythromycin and gastrointestinal motility. Lancet 1987;2: 1036.

26. Fraser R, Shearer T, Fuller J, Horowitz M, Dent J. Intravenous erythromycin overcomes small intestinal feedback on antral, pyloric and duodenal motility. Gastroenterology 1992; 103:114-9.

27. Annese V, Janssens J, Vantrappen G, et al. Erythromycin accelerates gastric emptying by inducing antral contractions and improved gastroduodenal coordination. Gastroenterology 1992;102:823-8.

28. Carlson RG, Hocking MP, Sninsky CA, Vogel SB. Erythromycin acts through a cholinergic pathway to improve caninedelayed gastric emptying following vagotomy and Roux-Y antrectomy. J Surg Res 1991;50:494-8.

29. Xynos E, Mantides A, Papageorgiou A, Fountos A, Pechlivanides G, Vassilakis JS. Erythromycin accelerates delayed gastric emptying of solids in patients after truncal vagotomy and pyloroplasty. Eur J Surg 1992;158:407-411.

30. Kepczyk T, Kadakia SC, Parker A, Pinkston T. Effect of intravenous erythromycin on gastric emptying. Gastrointest Endosc 1993;39:469-70.

31. Ramirez B, Eaker EY, Drane WE, Hocking MP, Sninsky CA. Erythromycin enhances emptying in patients with gastroparesis after vagotomy and antrectomy. Dig Dis Sci 1994;39: 2295-300.

32. Yeo CJ, Barry MK, Sauter PK, et al. Erythromycin accelerates gastric emptying after pancreaticoduodenectomy: a prospective, randomized, placebo-controlled trial. Ann Surg 1993;218:229-38.

33. Finley RJ, Inculet RI. The results of esophagogastrectomy without thoracotomy for adenocarcinoma of the esophagogastric junction. Ann Surg 1989;210:535-43.

34. Hankins JR, Attar S, Coughlin TR, et al. Carcinoma of the esophagus: a comparison of the results of transhiatal versus transthoracic resection. Ann Thorac Surg 1989;47:693-9.

35. Pac M, Basoglu A, Kocak $H$, et al. Transhiatal versus transthoracic esophagectomy for esophageal cancer. J THORAC CARDIOVASC SURG 1993;106:205-9.

36. Holscher AH, Voit H, Butterman G, Siewert JR. Function of the intrathoracic stomach as esophageal replacement. World J Surg 1998;12:835-44.

37. Morton KA, Karwande SV, David RK, Datz RL, Lynch RE. Gastric emptying after gastric interposition for cancer of the esophagus or hypopharynx. Ann Thorac Surg 1991;51:761-3.

38. Bonavina L, Anselmino M, Ruol A, Bardini R, Borsato N, Peracchia A. Functional evaluation of the intrathoracic stomach as an oesophageal substitute. Br J Surg 1992;79:529-32.

39. Casson AG, Powe J, Inculet R, Finley R. Functional results of gastric interposition following total esophagectomy. Clin Nucl Med 1991;12:918-22.

40. Hill ADK, Walsh TN, Hamilton D, et al. Erythromycin improves emptying of the denervated stomach after oesophagectomy. Br J Surg 1993;80:879-81.

\section{Discussion}

Dr. J. Kent Trinkle (San Antonio, Tex.). Dr. Burt, I would like to start out with one question. On several occasions I have encountered an atonic stomach after either a heart-lung or a bilateral lung transplant in which apparently I have either injured or cauterized both vagus nerves. Would erythromycin work in that situation? I remember one case in particular in which we tried every herb and unguent known to man and nothing worked.

Dr. Burt. Dr. Trinkle, to date there are very few clinical studies addressing your question. Erythromycin has been shown to promote gastric emptying after pancreatoduodenectomies in a randomized trial from The Johns Hopkins Hospital. It has been shown to promote gastric emptying after vagotomy and antrectomy. I would think that erythromycin would work in your patients if the gastroparesis is due to the vagi being injured.

Dr. Nasser Altorki (New York, N.Y.). Have you done any dose-response studies to determine how much erythromycin you need to give? I noticed you gave it intravenously. Is there a correlation between the blood levels after intravenous and oral administration? Finally, can you reflect on the possible mechanism of action?

Dr. Burt. Dr. Altorki, the mechanism of action is well documented. Erythromycin simulates the motilin receptor in the gastric antrum, leading to increased gastric emptying.

Regarding pharmacokinetics, we have no data, any nor have I found any study to document blood levels of erythromycin versus gastric emptying.

Erythromycin is effective orally. Hill and associates from Dublin have treated a group of patients after esophagogastrectomy, a standard Ivor Lewis procedure. They have shown that if you treat a patient for 3 days with $250 \mathrm{mg}$ orally, three times a day, gastric emptying will be markedly increased.

Dr. Mark K. Ferguson (Chicago, Ill.). I would like to express a couple of concerns. The first is in regard to the mix of gastric emptying procedures between the two groups and whether this might have had some effect on the emptying studies that you performed. Second, if the emptying is so poor in the control group, maybe you could explain to me the value of any of the emptying procedures. Finally, could you speculate as to the utility of oral doses of erythromycin in the acute period, and particularly on the absorption of erythromycin in those patients?

Dr. Burt. Regarding the different procedures, obviously these patients underwent esophagogastrectomy by the technique of choice of the surgeon and then entered the study. I had no control over the procedure done. However, there is no significant difference between the groups with regard to the procedure used.

This study was purposely done supine. Other published studies evaluated posture, emptying in the sitting or upright position 3 months to 12 months after operation. In these studies, gastric emptying is faster in patients who have had esophagectomy than in normal control subjects in the upright position but slower in the supine position.

This study was done in the supine position to see if the stomach could maintain peristalsis. Obviously, the stomach has little peristalsis when the vagi are cut; it needs a stimulant, and erythromycin is a very effective stimulant of gastric emptying in this situation. Erythromycin has been used anecdotally, at our institution and others, in patients in whom decreased gastric emptying has become a clinical problem ( $4 \%$ to $6 \%$ ). Erythromycin seems to allow these patients' stomachs to empty better so that they can go home instead of staying in the hospital until the stomach finally empties spontaneously. 
Erythromycin does work orally. It is absorbed in the small bowel, so it becomes a problem in these patients because it has to get into the small bowel. If a patient has a clinically significant paresis, we start with erythromycin intravenously and then switch to oral erythromycin.

Dr. Arthur N. Thomas (San Francisco, Calif.). We all know about the short efficacy of erythromycin from an antimicrobial aspect in the development of resistance. Obviously you are not going to use it in a long-term situation because of the danger of resistant organisms developing. I accept what you said for short-term use, but
I am curious about whether the motility has had any permanent change from this regimen months later.

Dr. Burt. Dr. Thomas, I personally have no data to address your question. There are data in patients with diabetic gastroparesis demonstrating that erythromycin given orally maintained its effect for 4 weeks. I know of no study following patients longer than that.

As far as the antibiotic effect, there are companies and institutions looking at developing a motilin stimulant structurally similar to erythromycin, but without its antibiotic properties. 